Check for updates

Cite this: New J. Chem., 2017, 41,9371

Received 19th May 2017 Accepted 24th July 2017

DOI: 10.1039/c7nj01751k

rsc.li/njc

\title{
Polyglycolide-montmorillonite as a novel nanocomposite platform for biosensing applications
}

\author{
Betul Unal, ${ }^{a}$ Esra Evrim Yalcinkaya, ${ }^{* b}$ Sila Gumustas, ${ }^{b}$ Burak Sonmez, ${ }^{a}$ \\ Melek Ozkan, ${ }^{\mathrm{C}}$ Mehmet Balcan, ${ }^{\mathrm{b}}$ Dilek Odaci Demirkol (D) ${ }^{\star a}$ and Suna Timur ${ }^{\mathrm{a}}$
}

\begin{abstract}
In catalytic biosensors, the immobilization of biomolecules in a suitable matrix is one of the vital parameters for obtaining improved systems. Clays, which are intercalated with various organic compounds, have a great tendency to develop biosensors with high stability, sensitivity and reproducibility. Herein, a polymer/clay nanocomposite based on natural silicate montmorilonite (Mt) and a biodegradable polymer polyglycolide (PGA) was prepared and characterized by FT-IR, thermogravimetric analysis, differential thermogravimetric analysis and $\mathrm{X}$-ray diffraction. Then, the resulting matrix was used as a fixation matrix for pyranose oxidase (POx), which was selected as a model enzyme. The bioactive layer was fabricated by immobilization of POx on glassy carbon electrodes by means of PGA-Mt and bovine serum albumin. The POx biosensor revealed a good linear range from 0.01 to $0.5 \mathrm{mM}$ glucose with a LOD of $1.2 \mu \mathrm{M}$. After the optimization of the working and preparation conditions, characterization studies were performed for glucose detection. Finally, the PGA-Mt/POx biosensor was confirmed to have detected glucose in beverages without needing any sample pre-treatment.
\end{abstract}

\section{Introduction}

Clays with their layered structures are ubiquitous compounds on the Earth's surface. ${ }^{1}$ Clays are commonly utilized as catalysts, adsorbents, energy-storage devices, drug carriers, immobilization matrixes, etc., for biological materials. ${ }^{2-6}$ Natural clays are divided into four main groups. Among them, montmorillonite (Mt), with tetrahedral-octahedral-tetrahedral structures, belongs to the subgroup of smectite, which is a member of the 2:1 phyllosilicates. $^{7}$ Mt has the widest application potential in bio-based detection technologies due to attainability, well identified intercalation/exfoliation chemistry, and high surface area. In our previous studies, methyl amine, dimethylamine, ${ }^{8}$ trimethylamine, ${ }^{9}$ amino acid (glycine, lysine, and glutamic acid, histidine), ${ }^{10,11}$ and calixarene ${ }^{12}$ intercalated Mt were used as attachment platforms to prepare glucose oxidase, pyranose oxidase (POx), laccase and microbial biosensors. Clay nanocomposites also have attracted a lot of attention in recent years. Exfoliation of clay layers using polymeric materials is the most

\footnotetext{
${ }^{a}$ Biochemistry Department, Faculty of Science, Ege University, 35100 Bornova-Izmir, Turkey.E-mail: dilek.odaci.demirkol@ege.edu.tr; Fax: +90 2323115485; Tel: +902323112455

${ }^{b}$ Chemistry Department, Faculty of Science, Ege University, 35100 Bornova-Izmir, Turkey. E-mail: esra.evrim.saka@ege.edu.tr; Fax: +90 2323888264; Tel: +902323111778

${ }^{c}$ Chemistry Department, IZTECH Faculty of Science, 35340 Urla-Izmir, Turkey
}

important element of working with clay nanocomposites. To prepare clay nanocomposites, various polymerization techniques have been developed such as in situ polymerization, solution casting, and melt processing. ${ }^{13-15}$ In the intercalative polymerization method, the monomer, initiator, and catalyst were put in layers of clays, and in situ polymerization was started thermally or chemically. ${ }^{16}$ After the formation of polymeric chains, nanocomposites were synthesized. Furthermore, several polymer/clay nanocomposites were reportedly used to design organo-clay structures such as polynorbornadiene/ $\mathrm{Mt},{ }^{17}$ polynorbornene/ $\mathrm{Mt}^{18}$ poly(lactic acid) (PLA)/poly( $\left(\varepsilon\right.$-caprolactone) (PCL)/Mt, ${ }^{19}$ $\operatorname{poly}(N$-vinylimidazole $) / \mathrm{Mt},{ }^{16}$ and poly(lactic acid)/sepiolite. ${ }^{20}$ Biomedical and biosensing applications of the prepared clay nanocomposites have gained increasing attention. For instance, Barlas et al. prepared a folate incorporated poly(e-caprolactone)/ clay nanocomposite, tested the matrix for discriminating cell adsorption and proliferation, and optimized it for cell proliferation and cytosensor platforms. ${ }^{21}$ In another study, poly lactateco-glycolide (PLGA)/Mt nanocomposites were developed; propranolol hydrochloride, an antihypertensive drug, was loaded; and Mt-PPN-PLGA nanocomposites were used as an oral controlled drug delivery system. ${ }^{22}$ Also, different from our study, using the montmorillonite clay mineral as a catalyst for the polymerization of glycolide was reported..$^{23}$ Nanocomposites have some advantages for use in bio-related areas because of their flexibility, biocompatibility and higher mechanical stability. Furthermore, 
the surface area of clay particles increases due to exfoliation of the clay layers in the polymer matrix, and it provides more interaction points between the matrix and biological materials during immobilization. These characteristics are key points in preparing biosensor systems without decreased activity of the biomolecules after immobilization. The success of immobilization directly affects the biosensor performance parameters such as operational or storage stability, detection limit, linear range for the analyte, selectivity, sensitivity, repeatability and reproducibility. By utilizing this fundamental knowledge, this was the first time that the clay-polymer nanocomposite was examined as an immobilization matrix for enzymes in biosensor construction. In this study, polyglycolide-montmorillonite (PGA-Mt) nanocomposites were synthesized via ring opening polymerization of glycolide monomer by the in situ method, and then, characterized and applied in biosensor preparation as an immobilization matrix. To the best of our knowledge, this will be the first study of the preparation and the biosensing application of PGA-Mt nanocomposites in which POx was used as a model enzyme for testing their applicability as an immobilization matrix and a biosensor component.

POx (pyranose: oxygen 2-oxidoreductase, EC 1.1.3.10, glucose 2-oxidase) is a member of the oxidoreductases and catalyzes the oxidation reaction of pyranoses at the C2 position. During the reaction of POx, oxygen is used as a co-substrate and hydrogen peroxide is the product. ${ }^{24,25}$ Both oxygen and hydrogen peroxide can be detected in electrochemical first generation enzymatic biosensors. To immobilize POx, various types of organic and inorganic materials, such as gold nanoparticle-polyaniline/AgCl/ gelatin nanocomposites, ${ }^{26}$ multiwalled carbon nanotube modified carbon pastes, ${ }^{27}$ calixarene-modified $\mathrm{Mt},{ }^{12}$ CTAB-modified dellite, ${ }^{28}$ manganese oxide decorated with platinum nanoparticles, ${ }^{29}$ and osmium redox polymers ${ }^{30}$ etc. were used in our previous studies. Also, different groups used POx in biosensor preparation, ${ }^{31}$ and biotechnological, clinical, and industrial applications ${ }^{32}$ due to lack of anomeric selectivity and its high affinity for D-glucose (in contrast to glucose oxidase).

Here, enzyme immobilization was performed on the glassy carbon electrode (GCE) using PGA-Mt by covalent bonding with glutaraldehyde and an inert protein (bovine serum albumin). After optimization of the PGA-Mt/POx biosensor, analytical characterization and sample application were carried out.

\section{Materials and methods}

\section{Materials}

Montmorillonite was from Southern Clay Products (NaMontmorillonite, CEC $=92 \mathrm{meq} / 100 \mathrm{~g}$, Gonzales, TX, USA). Na-Montmorillonite was dried under vacuum at $110{ }^{\circ} \mathrm{C}$ for $1 \mathrm{~h}$ and then it was used for modification. Tin(II) 2-ethyl-hexanoate $\left(\mathrm{Sn}(\mathrm{Oct})_{2}\right.$, Aldrich, 95\%) was used as received. All reactions and operations were performed using a glove box and conventional Schlenk tube techniques. Glycolide (GA, 97\%) was obtained from Aldrich and purified by recrystallization using dry ethyl acetate, dried under vacuum and kept under argon at $4{ }^{\circ} \mathrm{C}$.
The commercial solvents were distilled under argon atmosphere prior to use. Pyranose oxidase (POx; pyranose:oxygen 2-oxidoreductase, E.C. 1.1.3.10, from Coriolus sp., 10.4 units per mg solid), D-(+)-glucose, bovine serum albumin (BSA), glutaraldehyde solution $(25 \%, \mathrm{v} / \mathrm{v})$, ethanol, toluene (99\%), ethyl acetate $(99.8 \%)$, ascorbic acid (99\%), uric acid (99\%), 3-acetamidophenol (97\%), monosodium phosphate $\left(\mathrm{NaH}_{2} \mathrm{PO}_{4}\right)$, potassium ferricyanide(III) $\left(\mathrm{K}_{3} \mathrm{Fe}(\mathrm{CN})_{6}, 99.9 \%\right.$ ), potassium chloride (KCl) (St. Louis, MO, USA) and glucose liquicolor kits were purchased from SigmaAldrich and Human Diagnostics Worldwide (Wiesbaden, Germany), respectively. All other chemicals were analytical grade.

\section{Instrumentation}

Fourier transform infrared (FT-IR) spectra of PGA, Mt and PGA-Mt were recorded using a Perkin Elmer Pyris 1 FTIR Spectrometer with $\mathrm{KBr}$ discs. Thermogravimetric analysis (TGA/DTG) was performed using a Perkin-Elmer Diamond TA/TGA to determine the thermal strength. Five to eight milligrams of sample were heated from 50 to $900{ }^{\circ} \mathrm{C}$ using a scan speed of $10{ }^{\circ} \mathrm{C} \mathrm{min}^{-1}$ under nitrogen flow. X-ray diffraction (XRD) analysis was performed on a Panalytical X'Pert ProMaterials Research Diffractometer with $\mathrm{CuK} \alpha$ radiation $(\lambda=1.5406 \AA)$. The $2 \theta$ angles were varied between $3^{\circ}$ and $60^{\circ}$. The surface appearance was explored with a FEI Quanta250 FEG scanning electron microscope (SEM). SEM-EDX analysis was performed with a Philips XL-30S FEG. AFM images were taken with a NanoSurf Flex Axiom. For the preparation of AFM samples, a $1.0 \mathrm{mg} \mathrm{mL} \mathrm{m}^{-1}$ solution of PGA-Mt (1.0\% Mt in nanocomposite) was spread onto indium tin oxide (ITO) using a spin-coater (Laurell Spin Coater XS650). The wettability of the PGA-Mt and PGA-Mt/ POx was measured at room temperature in an Attension Tensiometer by the sessile drop method. Water drops of $5.0 \mu \mathrm{L}$ were placed at numerous locations of triplicate samples and the contact angle was documented. To measure the contact angles of PGA-Mt, solutions of the nanocomposites were prepared and dropped onto ITO surfaces. After drying the samples, the angles were measured. A JEOL JEM-1010 (JEOL Ltd, Tokyo, Japan) transmission electron microscope was used to take TEM images of PGA-Mt. For this purpose, $0.3 \mu \mathrm{m}$ thick sections were cut on a Leica ultramicrotome using glass knives.

A PalmSens Electrochemical Measurement System (Palm Instruments, Houten, Netherlands) was used for amperometric and cyclic voltammetric (CV) measurements and a CHI6005 C electrochemical unit ( $\mathrm{CH}$ Instruments Incorporation, Austin, Texas, USA) was utilized for impedimetric (EIS) analysis at room temperature. A triple electrode system was configured in all measurements: glassy carbon electrode (GCE) (BASi, West Lafayette, Indiana), platinum (Pt) electrode (BASi, West Lafayette, Indiana) and $\mathrm{Ag} / \mathrm{AgCl}(3.0 \mathrm{M} \mathrm{KCl}$ saturated with $\mathrm{AgCl}$ as an internal solution, Metrohm, Switzerland) as the working, counter and reference electrodes, respectively. A Millipore Milli-Q Ultrapure Water System was used to prepare water.

\section{Synthesis of polyglycolide-Mt (PGA-Mt) nanocomposites}

Mt (23 mg, corresponding to $1.0,2.0$, or $3.0 \%$ of the monomer by weight) was placed in Schlenk tubes equipped with a magnetic stirrer under $\mathrm{Ar}$ atmosphere and dispersed in dry toluene 
(5.0 $\mathrm{mL})$. Glycolide (GA) was dried under high vacuum (5.0 mmHg) for half an hour at $50{ }^{\circ} \mathrm{C}$ before use. Then, $0.23 \mathrm{~g}$ $(2.0 \mathrm{mmol}) \mathrm{GA}$ monomer and $\left[\mathrm{Sn}(\mathrm{Oct})_{2}\right](1 / 100$ molar ratio with respect to monomer) were added to the Schlenk tubes that contained Mt. The reactions were carried out at $110{ }^{\circ} \mathrm{C}$ for $4 \mathrm{~h}$.

The Schlenk tubes were immersed in liquid nitrogen to stop the action. The polymerization conditions were assigned according to the maximum polymerization yields. The nanocomposites were precipitated in an excess amount of cold methanol. The products were separated with ultracentrifugation followed by washing with methanol several times with $88 \%$ conversion. They were then dried in a vacuum oven overnight.

\section{Preparation of PGA-Mt/POx biosensors}

$1.0 \mathrm{mg}$ POx, $5.0 \mu \mathrm{L}$ of sodium phosphate buffer (PB; $50 \mathrm{mM}$, $\mathrm{pH} 7.0), 5.0 \mu \mathrm{L}$ of PGA-Mt $\left(1.0 \mathrm{mg} \mathrm{mL}^{-1}\right.$ in $\left.\mathrm{PB}\right), 3.0 \mu \mathrm{L}$ BSA (1.0 $\mathrm{mg} \mathrm{mL}^{-1}$ in $\mathrm{PB}, 50 \mathrm{mM}$, pH 7.0), and $2.5 \mu \mathrm{L}$ glutaraldehyde (5.0\% in PB $50 \mathrm{mM}, \mathrm{pH} 7.0)$ were stirred in a tube. Then the mixture was dropped onto the working electrode surface. The electrode surface was dried at room temperature for $1 \mathrm{~h}$. A summary of the modification steps of clay with glycolide and biosensor preparation is shown in Scheme 1.

\section{Measurements}

All amperometric signals were recorded with the current (I, $\mu \mathrm{A})$ at $-0.7 \mathrm{~V}$ and carried out in $10 \mathrm{~mL}$ of the working buffer solution at room temperature under gentle stirring (sodium phosphate buffer (PB) $\mathrm{pH}$ 6.0, $50 \mathrm{mM}$ ). $50 \mathrm{mM}$ was chosen as a working buffer concentration according to the previous studies in enzymatic biosensing technologies and POx biosensors. ${ }^{12,26-28,30,33}$

The electrodes were cleaned with distilled water and kept in the working buffer for $3 \mathrm{~min}$ after each measurement. After the signal was stable, the analyte (glucose) was injected into the working cell. The POx catalysis oxidation reaction of glucose to its oxidized product and currents was connected to consumed oxygen amounts during the POx reaction. The electrodes were

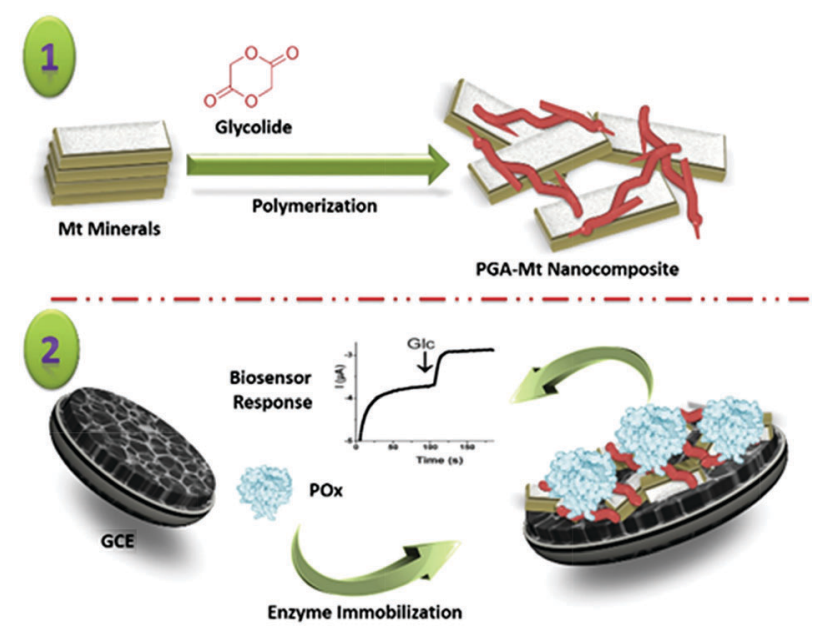

Scheme 1 Schematic representation of step by step preparation of the PGA-Mt/POx biosensor. cleaned by washing with water and the buffer was revitalized after each measurement. $\mathrm{CV}$ analysis was carried out in $50 \mathrm{mM}$ $\mathrm{PB}\left(\mathrm{pH} 6.0\right.$ and $\left.5.0 \mathrm{mM} \mathrm{K}_{3} \mathrm{Fe}(\mathrm{CN})_{6}\right)$ at the potential range of $-0.4 \mathrm{~V}$ to $+0.8 \mathrm{~V}$ in the presence of using $0.1 \mathrm{M}$ potassium chloride as the auxiliary electrolyte. EIS measurements were carried out in a frequency range from $0.3 \times 10^{-4}$ to $10 \mathrm{kHz}$ at $0.18 \mathrm{~V}$ excitation voltage in $50 \mathrm{mM} \mathrm{PB}(\mathrm{pH}$ 6.0) including $5.0 \mathrm{mM} \mathrm{K} \mathrm{K}_{3} \mathrm{Fe}(\mathrm{CN})_{6}$ and $0.1 \mathrm{M} \mathrm{KCl}$. The concentration of glucose in real samples such as Coke and other fizzy drinks was calibrated using a standard glucose solution and compared with the result obtained by the spectrophotometric glucose kits based on the Trinder Reaction. ${ }^{34}$

\section{Results and discussion}

\section{Morphology and chemistry of PGA-Mt nanocomposites}

Polyglycolide (PGA), which is produced from renewable resources such as corn starch and sugar, is a biodegradable polymer. PGA and copolymers are biodegradable ingredients and are particularly used in the preparation of medicines and pharmaceutics. Their biocompatibility increases their usage potential in surgical materials, bone tissue engineering, and drug release studies as microspheres. ${ }^{35,36}$ PGA synthesis can be carried out by ring-opening polymerization methods using different catalysts.

Synthesis of PGA is carried out generally with the use of tin compounds such as tin(II) 2-ethylhexanoate $\left(\mathrm{Sn}(\mathrm{Oct})_{2}\right)$, which is accepted by the Food and Drug Administration as a food additive. ${ }^{37}$ When PGA-clay nanocomposites are compared to virgin polymers, they are valuable alternatives due to their wide application areas in technology. Herein, the PGA-Mt nanocomposite was prepared via ring opening polymerization of GA initiated by $\mathrm{Sn}(\mathrm{Oct})_{2}$ and the presence of Mt (Scheme 1) using the in situ polymerization method. FTIR, XRD, TGA/DTG, SEM, SEM-EDX, TEM and AFM techniques were used to characterize the PGA-Mt nanocomposite. As seen from Fig. 1, the neat Mt showed the typical stretching band for $\mathrm{Al}-\mathrm{Al}-\mathrm{OH}$ at $3630 \mathrm{~cm}^{-1}$. The bands at around 3433 and $1600 \mathrm{~cm}^{-1}$ are assigned to the $\mathrm{H}-\mathrm{OH}$ stretching vibration of adsorbed water. It presented a

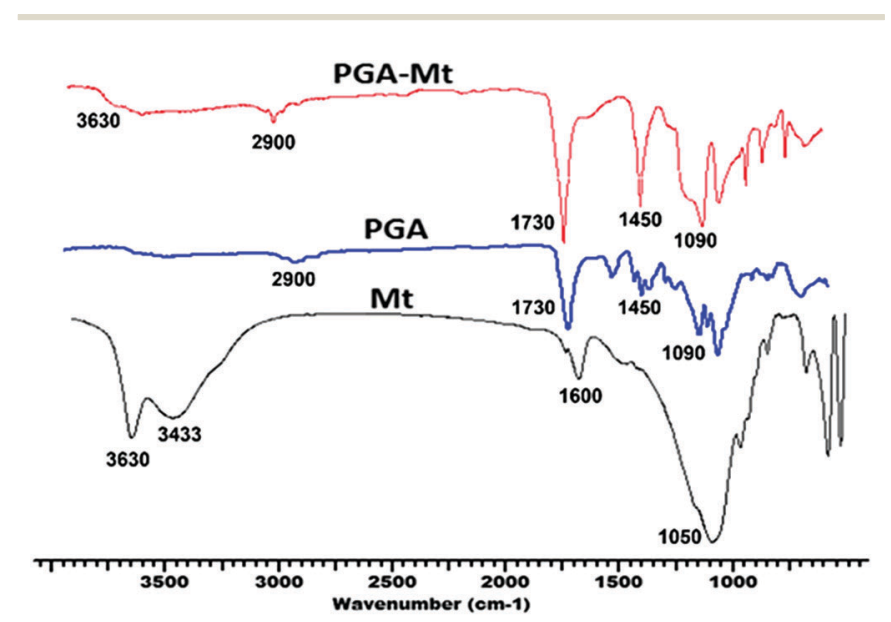

Fig. 1 FTIR profile of Mt, PGA and the PGA-Mt nanocomposite. 
broadly similar shape of absorption at $1050 \mathrm{~cm}^{-1}$ arising from Si-O stretching vibrations. The olefinic $\mathrm{C}-\mathrm{H}$ stretching band of neat PGA was observed at about $2900 \mathrm{~cm}^{-1}$ in the FTIR spectrum. Also, the strong stretching vibration of the $\mathrm{C}=\mathrm{O}$ carbonyl group at $1730 \mathrm{~cm}^{-1}$, the wagging of the $-\mathrm{CH}_{2}$ groups at $1500-1400 \mathrm{~cm}^{-1}$, and the $\mathrm{C}-\mathrm{O}-\mathrm{C}$ stretching band on chair at about $1090 \mathrm{~cm}^{-1}$ were observed respectively. Besides these verifications for the PGA-Mt nanocomposite, the spectra show all these characteristic groups of Mt and PGA with increased intensity of the absorption band.

The nanocomposite structure was also investigated by the XRD method (Fig. 2). According to the results of XRD, unlike those from the neat $\mathrm{Mt}$, the absence of any $d_{001}$ reflection in the XRD pattern of the nanocomposite proves the presence of an exfoliated structure. The presence of exfoliation can refer to good compatibility of the PGA with the clay mineral at this clay content. The thermal behaviour of PGA and the PGA-Mt nanocomposites was investigated by TGA. According to the TGA curves (Fig. 3A), the stability of the nanocomposite was enhanced when compared to the neat PGA. This increment of thermal stability is related to the nanodispersion of the silicate in the polymer matrix. Remarkably, the final char yields of the PGA were increased from $3.2 \%$ to $4.5 \%$ by adding clay. Fig. $3 \mathrm{~B}$ shows DTG curves of pure PGA and the PGA-Mt nanocomposite. Both of the samples displayed one of the degradation stages in the range of $300-350{ }^{\circ} \mathrm{C}$. The degradation peak of the PGA appeared as a shoulder in the PGA-Mt thermogram due to the low clay content. The max peak degradation temperatures were determined as 285 and $305{ }^{\circ} \mathrm{C}$ for pure PGA and the PGAMt nanocomposite, respectively. This indicates that there was an increase in the thermal stability of the PGA-Mt nanocomposite due to the presence of the clay. The improvement in thermal degradation was usually more significant for linear polymer matrixes with the addition of nanoclay. In the presence of clay platelets, polymer chains come near clay nanoplatelets and molecular actions are limited. Hence, the thermal stability was improved for these polymer chains. ${ }^{38,39}$

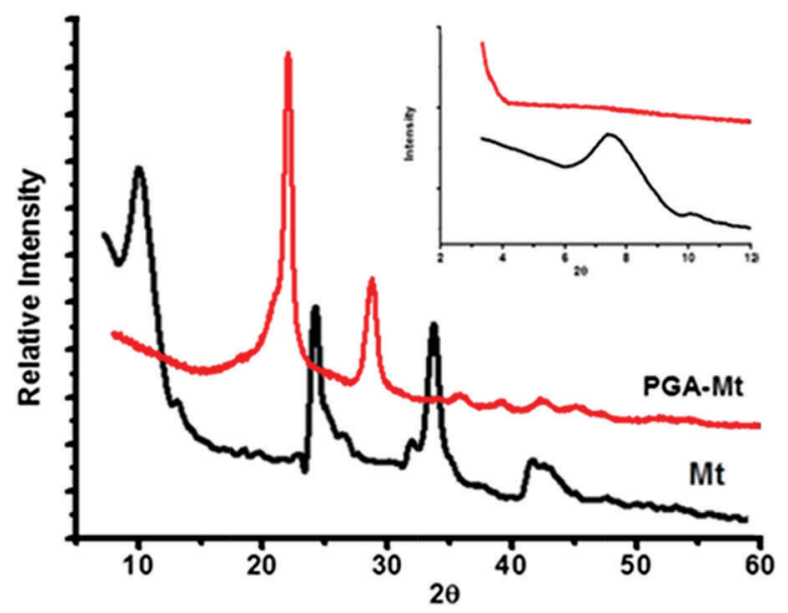

Fig. 2 X-ray diffractions of $M t$ and the PGA-Mt nanocomposite. (Inset shows XRD pattern with $2 \theta=2-10$ scale.)
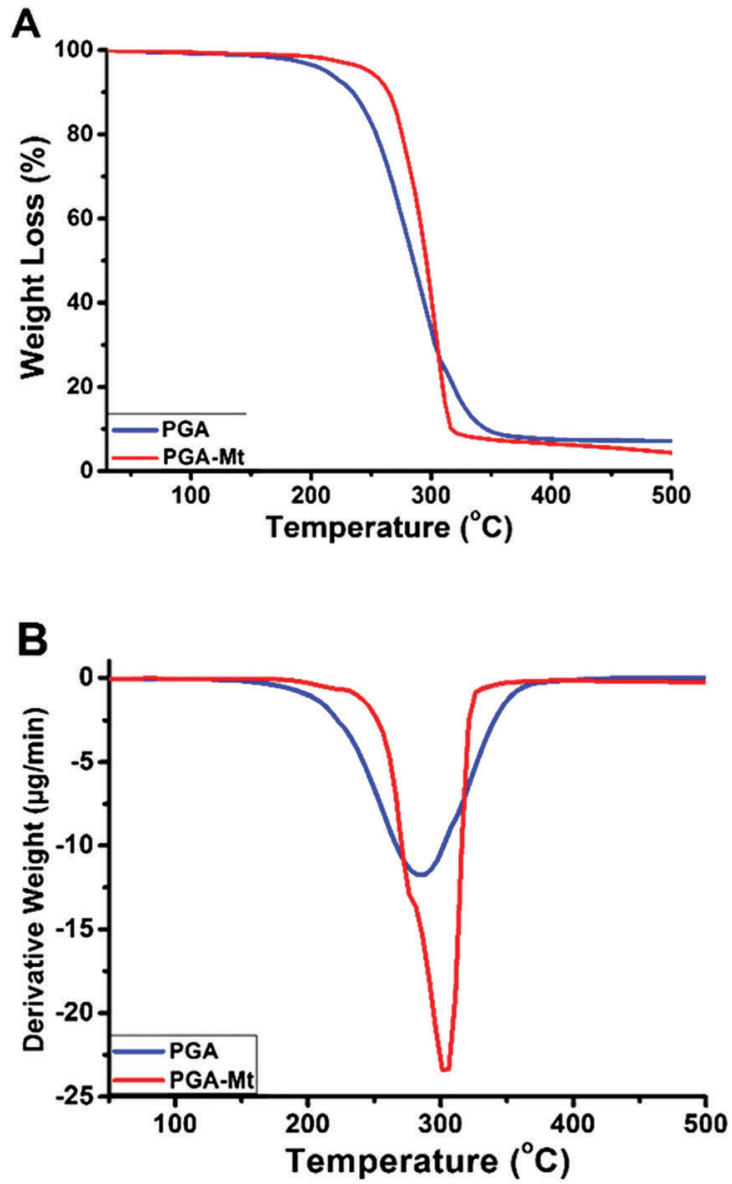

Fig. 3 (A) TGA, and (B) DTG thermograms of pure PGA and the PGA-Mt nanocomposite.

It was clear that the XRD analysis was insufficient for the complete identification of the nanocomposite structures because of the low amount of nanoclays. It should be supported by transmission electron microscopy (TEM) that was capable of directly identifying the particles that were undetectable using $\mathrm{XRD}$ analysis. To more clearly assign exfoliated structures of the nanocomposites, a TEM analysis of the PGA-Mt nanocomposite was performed (Fig. 4A). In the TEM image, the silicate layers are represented by the dark lines whereas the polymer matrix is indicated as the brighter area.

The clay platelets were well dispersed in the polymer matrix due to the connected catalyst and monomer in the layer of clay particles for the PGA-Mt nanocomposite. It is clear that the exfoliated clay platelets (highlighted by a black arrow) were distributed in the polymer matrix after a large quantity was observed, and this observation was also compatible with the XRD results. The size of the clay layers was $\sim 3.0 \mathrm{~nm}$ thick and $60 \mathrm{~nm}$ long. AFM is the one of the most useful techniques for determining the clay dispersion in a PGA matrix while also supporting TEM for the analysis of nanocomposites. ${ }^{21,40}$ AFM images of PGA-Mt nanocomposites using the tapping mode are depicted in Fig. 4B. According to this image, disc shaped objects of about $70-80 \mathrm{~nm}$ can be attributed to the clay particles, and the highlighted parts in the inset of Fig. 4B show the polymer chains. 

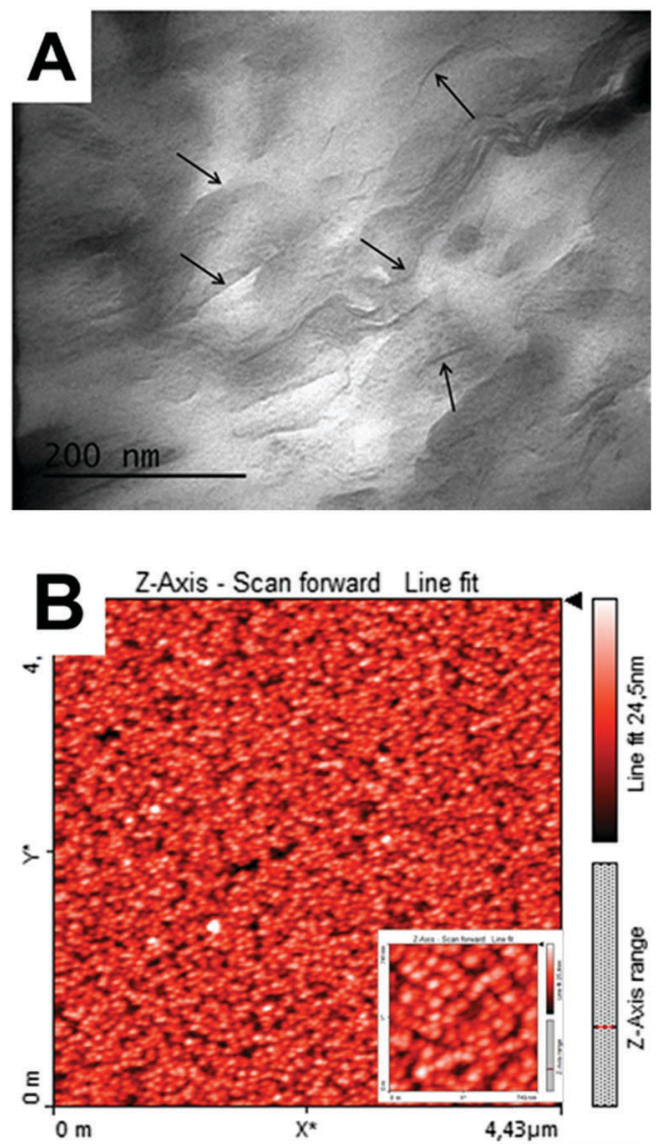

Fig. 4 (A) TEM micrographs of the PGA-Mt nanocomposite. (B) AFM image of the PGA-Mt nanocomposite $(5 \times 5 \mu \mathrm{m}$ and inset figure is $1 \times 1 \mu \mathrm{m})$.

\section{Surface characterization of PGA-Mt/POx biosensors}

$\mathrm{CV}$ and EIS techniques were utilized for the determination of the surface characteristics and electron transfer mechanisms of modified GCE. EIS is a significant method for observing electrode surfaces after modification. Thus, impedimetric analysis was followed in $\mathrm{PB}(50 \mathrm{mM}, \mathrm{pH}$ 6.0) including using $5.0 \mathrm{mM} \mathrm{K}_{3} \mathrm{Fe}(\mathrm{CN})_{6}$ as a redox probe and $0.1 \mathrm{M} \mathrm{KCl}$ as the auxiliary electrolyte. The impedance spectra of bare, PGA-Mt, and PGA-Mt/POx modified electrodes (Fig. 5A) were recorded in the range of frequency from $0.21 \times 10^{-4}$ to $100 \mathrm{kHz}$, using a discontinuous current (ac) signal amplitude at a direct current (dc) bias of $10 \mathrm{mV}$. As seen in Fig. 5A, the bare GCE had the smallest semicircle diameter. The charge transfers resistance $\left(R_{\mathrm{ct}}\right)$ values of the bare, PGA-Mt, and PGA-Mt/POx electrodes were measured as $472 \Omega, 594.5 \Omega$, and $756 \Omega$ respectively. The semicircle diameter defines the electron-transfer resistance $\left(R_{\mathrm{et}}\right)$, and its meaning indicates a faster electron transfer than for PGA-Mt and PGA-Mt/POx. In order to support these results, CV analysis was performed under the same working conditions. The measurements were used to analyse oxidation and reduction current peaks in the potential range of $-0.4 \mathrm{~V}$ to +0.8 (Fig. $5 \mathrm{~B}$ ). The peak potential separations were calculated for bare, PGA-Mt and PGAMt/POx modified GC electrodes as 323, 380 and $730 \mathrm{mV}$, respectively. The modification of GC surfaces with PGA-Mt and
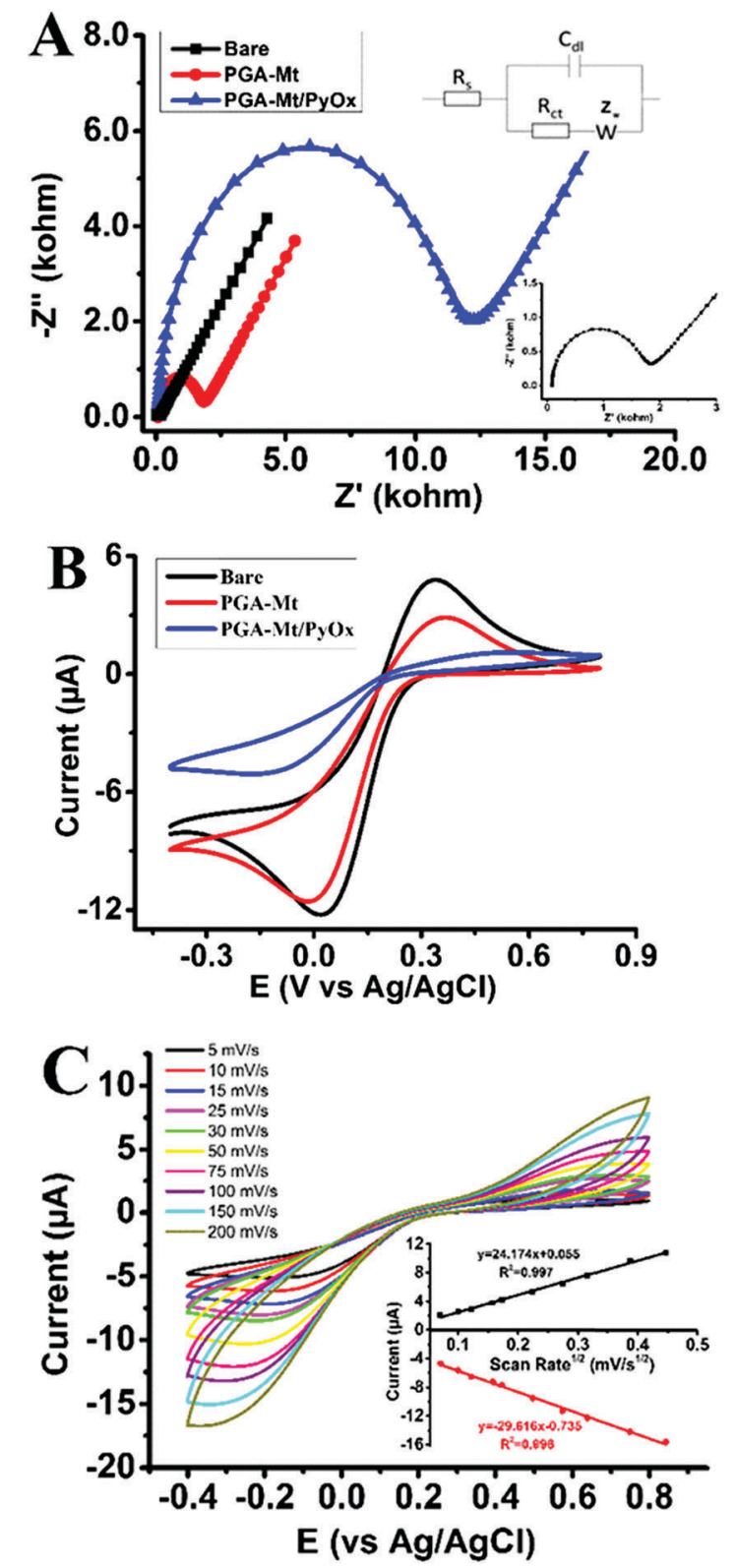

Fig. 5 (A) Profiles for EIS originated from bare, PGA-Mt and PGA-Mt/POx modified electrodes in $50 \mathrm{mM} \mathrm{PB}\left(\mathrm{pH} 6.0\right.$; including $5.0 \mathrm{mM}, \mathrm{K}_{3} \mathrm{Fe}(\mathrm{CN})_{6}$ and $0.1 \mathrm{M} \mathrm{KCl}$ ) at $0.18 \mathrm{~V}, 0.21 \times 10^{-4}-100 \mathrm{kHz}$. (B) Cyclic voltammograms of bare, PGA-Mt and PGA-Mt/POx covered electrodes (in $5.0 \mathrm{mM} \mathrm{K} \mathrm{K}_{3} \mathrm{Fe}(\mathrm{CN})_{6}$ at a scan rate of $5.0 \mathrm{mV} \mathrm{s}{ }^{-1}$ ). (C) $\mathrm{CV}$ results of PGA-Mt/POx modified electrodes at varying scan rates [the supplemental graph depicts the association between the sensor response and square root of the scan rates $(5,10$, $\left.\left.15,25,30,50,75,100,150,200 \mathrm{mV} \mathrm{s}^{-1}\right)\right]$.

PGA-Mt/POx caused shifts in the anodic and cathodic peak potentials; these results are in harmony with the previous studies. ${ }^{29,41}$ The influence of the scan rate on the biosensor response was depicted in Fig. 5C. PGA-Mt/POx presented diffusion controlled behaviour between $5-200 \mathrm{mV} \mathrm{s}^{-1}$ scan rates, with an equation equal to $y=24.174 x+0.055,\left(R^{2}=0.997\right)$ for $I_{\text {anodic }}$ and $y=-29.616 x-2.735,\left(R^{2}=0.996\right)$ for $I_{\text {cathodic }}{ }^{8,12,28}$

The morphology and dispersion of the samples were investigated by SEM. SEM images of the prepared PGA-Mt nanocomposites 
and PGA-Mt/POx modified electrodes are indicated in Fig. 6. For the immobilization of POx glutaraldehyde was used as a crosslinking agent that binds amino groups of amino acids in the structure of enzymes (here POx) and proteins (BSA). ${ }^{42}$ The immobilization of POx on the surface of the GCE using PGA-Mt was carried out covalently. ${ }^{43}$ After modification of the surfaces with POx using PGA-Mt via crosslinking, SEM-EDX analysis was carried out to prove the success of immobilization. POx is a $\mathrm{H}_{2} \mathrm{O}_{2}$ generating flavoprotein. ${ }^{12,25-30}$ Because of the presence of phosphate groups in the flavinadeninedinucleotide (FAD) structure of flavoproteins, $\mathrm{P}$ peaks of $\mathrm{FAD}$, and $\mathrm{N}$ peaks of proteins were shown in the EDX diagrams (Fig. 6A). After treatment of the polymer with the clay, some clay aggregates with bright regions are observed on the surface of the PGA-Mt nanocomposite in Fig. 6B and C. In addition, the SEM micrograph of the PGA-Mt/POx is shown in Fig. 6C. After immobilization of the enzyme, it was clearly observed that the PGA-Mt/POx covered electrodes demonstrated a rough surface.

\section{Optimum pH}

Working in appropriate $\mathrm{pH}$ is an important point for the enzymatic biosensors. To obtain the optimum $\mathrm{pH}$ value for the PGA-Mt/POx biosensors, sodium acetate (50 mM; pH 4.0-5.5) and PBs (50 mM; pH 6.0-7.0) were used as a working solution, and the biosensor response for glucose was monitored in different pHs. The results are given in Fig. 7, and according to the profile, the optimum $\mathrm{pH}$ was 6.0. The optimum $\mathrm{pH}$ values for POx biosensors were found to be $10.5,7.5$, and 6.0 in the literature. ${ }^{12,25-29}$ It can be said that the optimum $\mathrm{pH}$ was affected by the nature of the immobilization matrix.

\section{Influence of enzyme and clay amounts on the current of PGA-Mt/POx}

Modulation of the amount of enzyme in the layer of electrode surfaces is necessary to obtain maximum sensitivity. For this aim, the electrodes were modified with various POx amounts such as $0.5 \mathrm{mg}, 1.0 \mathrm{mg}$ and $2.0 \mathrm{mg}$ (activity of enzymes was 10.4 units per mg solid) in order to determine the optimum enzyme amount. The biosensor response was recorded for different glucose concentrations between 0.01 and $1.0 \mathrm{mM}$ (Fig. 8A). When $0.5 \mathrm{mg}$ of POx enzyme was used on the immobilization layer, a current change after the addition of the substrate did not occur. The highest current responses were obtained using $1.0 \mathrm{mg}$ POx while preparing the PGA-Mt/POx biosensor. When insufficient enzyme amount is used, a current change did not occur after substrate addition. Increase in the POx amount caused an increase in biosensor response. When $2.0 \mathrm{mg}$ of enzyme was used, the biosensor response decreased because of the occurrence of the diffusion limit for substrate and oxygen (co-substrate). The obtained results using PGA-Mt/POx are in agreement with previous studies. ${ }^{12,28,44-46}$

Another important parameter to find optimum preparation conditions in enzymatic biosensors is the amount of immobilization matrix. ${ }^{46-48}$ To test the influence of clay amount on the response, different POx biosensors were prepared using 1.0, 2.0, and $3.0 \%$ clay in the nanocomposites and calibration curves for

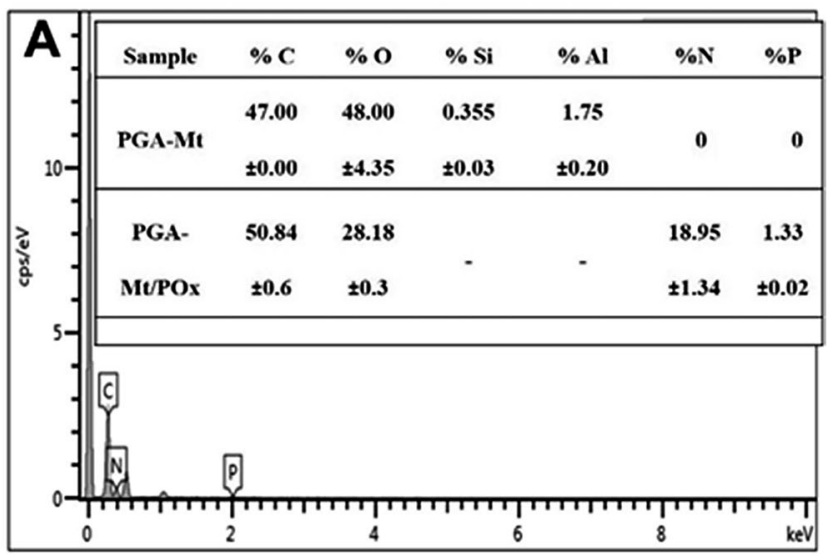
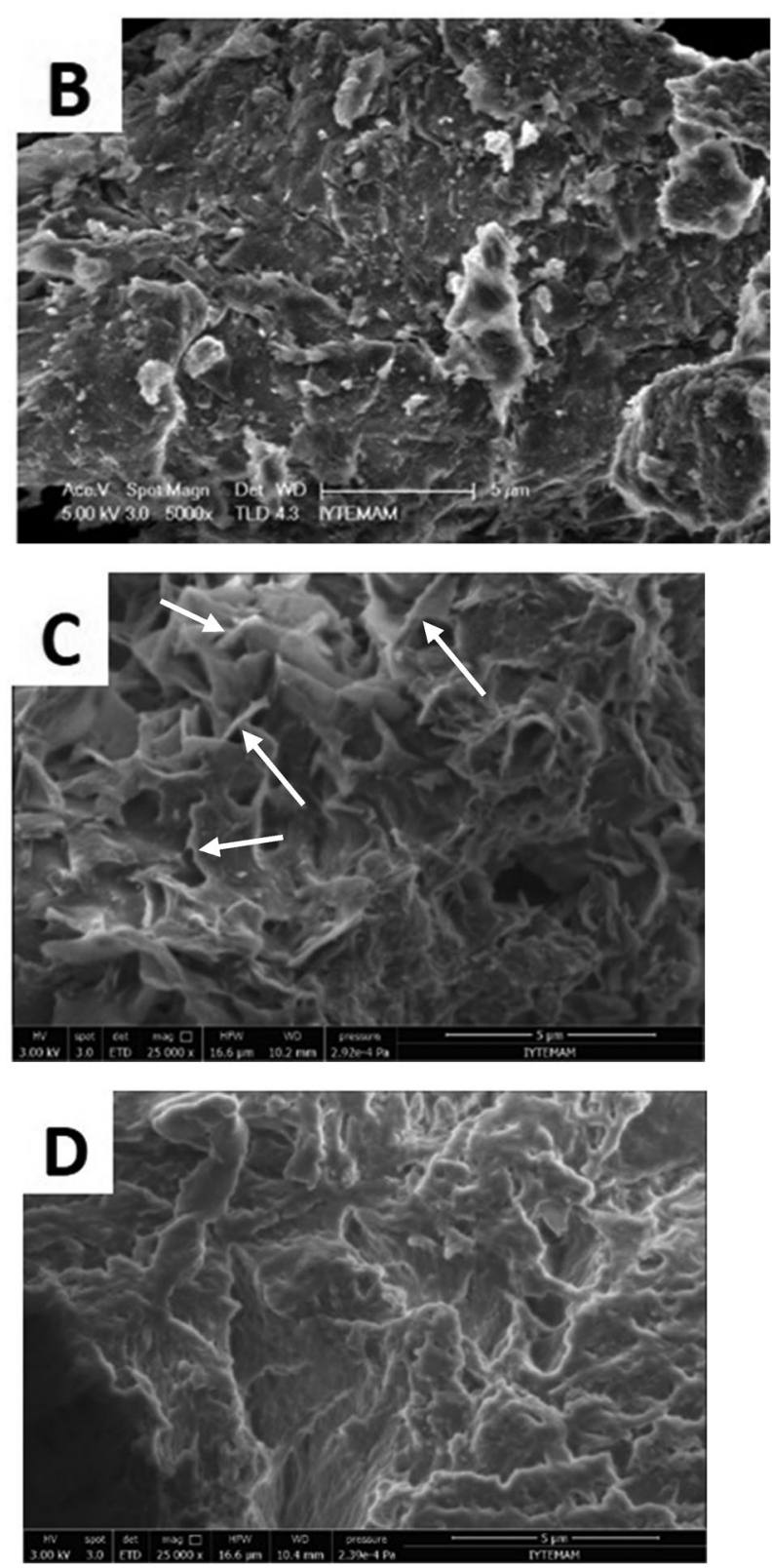

Fig. 6 (A) SEM-EDX results of PGA-Mt and PGA-Mt/POx, and SEM images of (B) Mt, (C) PGA-Mt, and (D) PGA-Mt/POx. 


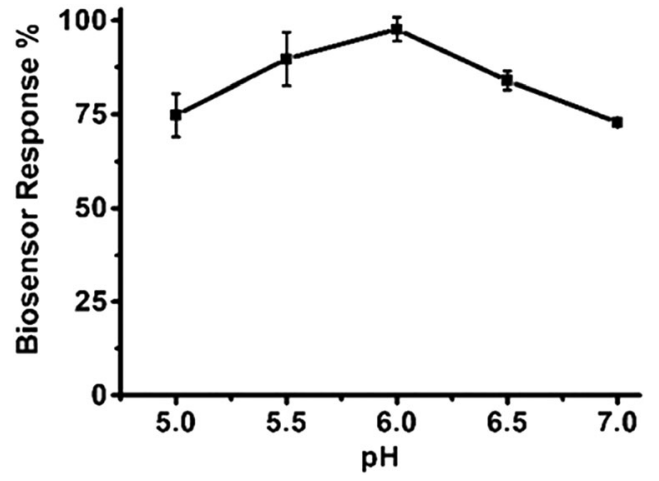

Fig. 7 Optimum pH of PGA-Mt/POx (working potential: $-0.7 \mathrm{~V}$; error bars indicate S.D. of 3 trials; in $50 \mathrm{mM}$ sodium acetate and PBs and using of $0.1 \mathrm{mM}$ glucose as substrate).
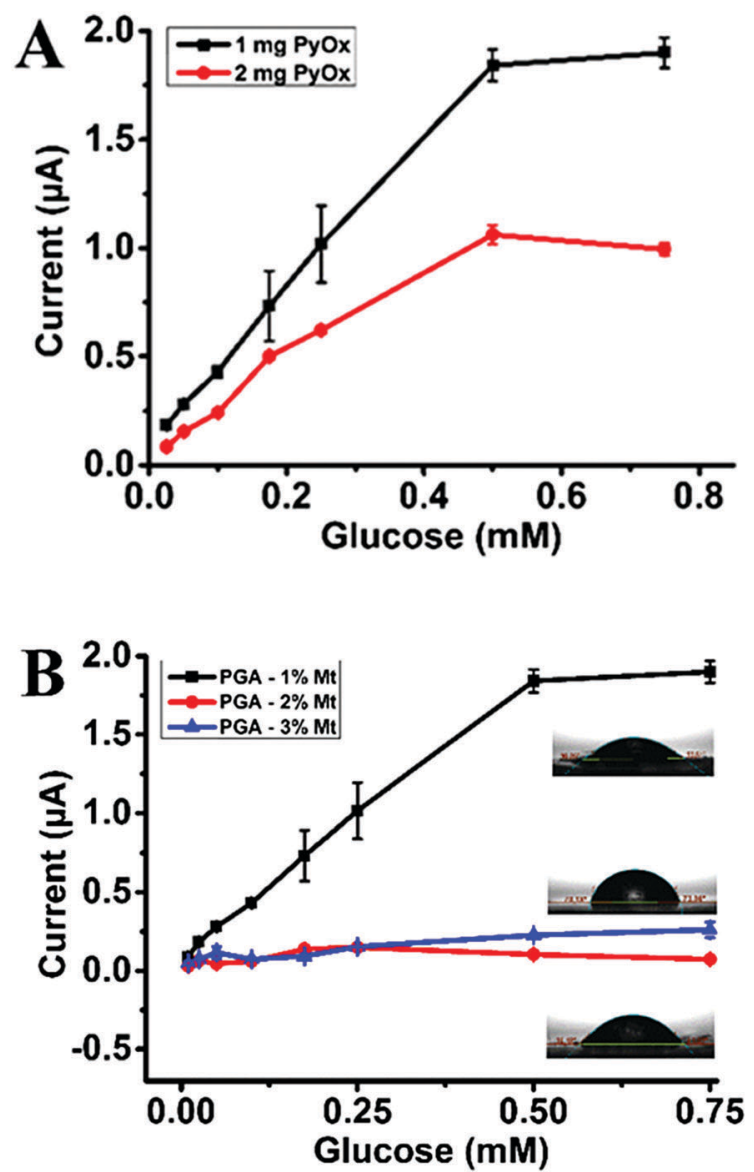

Fig. 8 (A) Effect of enzyme amount and (B) clay amount in the nanocomposite on the current response of PGA-Mt/POx (in PB, $50 \mathrm{mM}, \mathrm{pH} 6.0$, at $-0.7 \mathrm{~V}$; error bars indicate S.D. of three replicates. Insets: Contact angles of each clay amounts).

glucose were formed. According to Fig. 8B, the highest current values were obtained using $1.0 \%$ of $\mathrm{Mt}$ in the nanocomposites. The film thickness changes with the change of the clay amount on the electrode surface. The biosensor response decreases with an increase in thickness (increase in clay amount) as previously observed for clay-based enzymatic biosensors. A thicker bioactive layer causes a poor amperometric response. This can be attributed to the diffusion barrier for the substrates (glucose) and co-substrates (molecular oxygen) of the enzyme. ${ }^{46,49,50}$ Also, the contact angles of different PGA-Mt and PGA-Mt/POx surfaces were measured, and $8.0-10^{\circ}$ was obtained for $1.0,2.0$, and $3.0 \%$ of $\mathrm{Mt}$ in the nanocomposites. After the POx immobilization, $30.61^{\circ}, 43.02^{\circ}$ and $73.08^{\circ}$ were obtained with $1.0,2.0$, and $3.0 \%$ Mt in the nanocomposites, respectively.

\section{Analytical characterization}

The linear range obtained with the PGA-Mt/POx biosensors was from 0.01 to $0.5 \mathrm{mM}$ glucose concentrations with the equation of $y=3.549 x+0.092\left(R^{2}=0.998\right)$ (Fig. 9). The limit of detection (LOD) for glucose was $1.2 \mu \mathrm{M}$ glucose. For determination of operational stability, 158 trials were implemented by injecting $0.1 \mathrm{mM}$ analyte (glucose) over 144 hours, and a $27 \%$ decrease in the biosensor response of the developed system was observed. The S.D. and variation coefficient (cv) were determined to be $\pm 0.004 \mathrm{mM}$ and $4.08 \%$, respectively. A comparison of the analytical performance of the POx biosensors is summarized in Table 1.

\section{Interferences}

Most metabolites can be oxidized and interfered with at high working potentials. Thus, several compounds such as uric acid $(0.1 \mathrm{mM})$, ascorbic acid $(0.1 \mathrm{mM})$, ethanol $(0.1 \mathrm{mM})$, and 3-acetamidophenol $(0.1 \mathrm{mM})$ were used to investigate the effects of interferents on the PGA-Mt/POx biosensor response under the working conditions. According to the results, meaningful interference of the biosensor response for glucose did not occurr (Fig. 10).

\section{Sample application}

The glucose content of some non-alcoholic beverages, for example, Coke and other fizzy drinks, was analysed by the PGA-Mt/POx biosensor. The beverages were degassed, diluted, and then added to the working solution as a substrate without any dilution. To check the results obtained with PGA-Mt/POx, a spectrophotometric

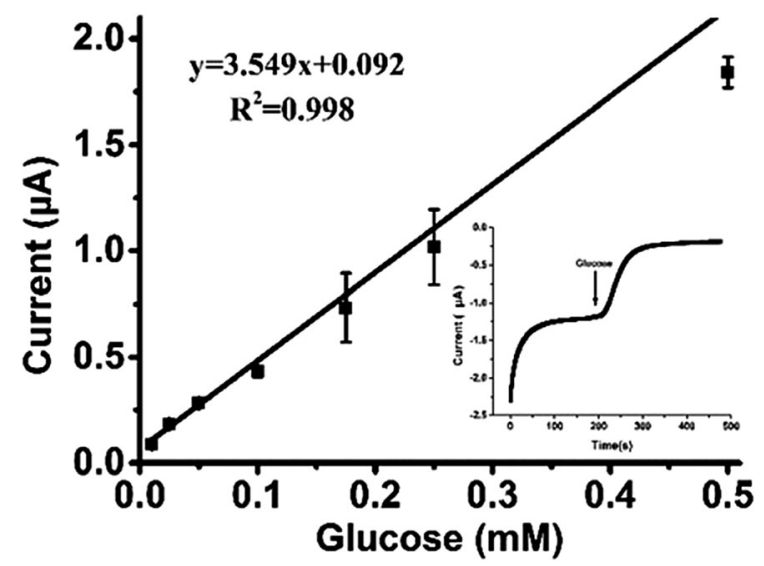

Fig. 9 Linearity for glucose (in $50 \mathrm{mM} \mathrm{pH} 6.0 \mathrm{~PB},-0.7 \mathrm{~V}$; error bars show S.D. of three replicates. Supplement: time versus amperometric signal with the injection of $0.5 \mathrm{mM}$ glucose). 
Table 1 Comparison of POx biosensors

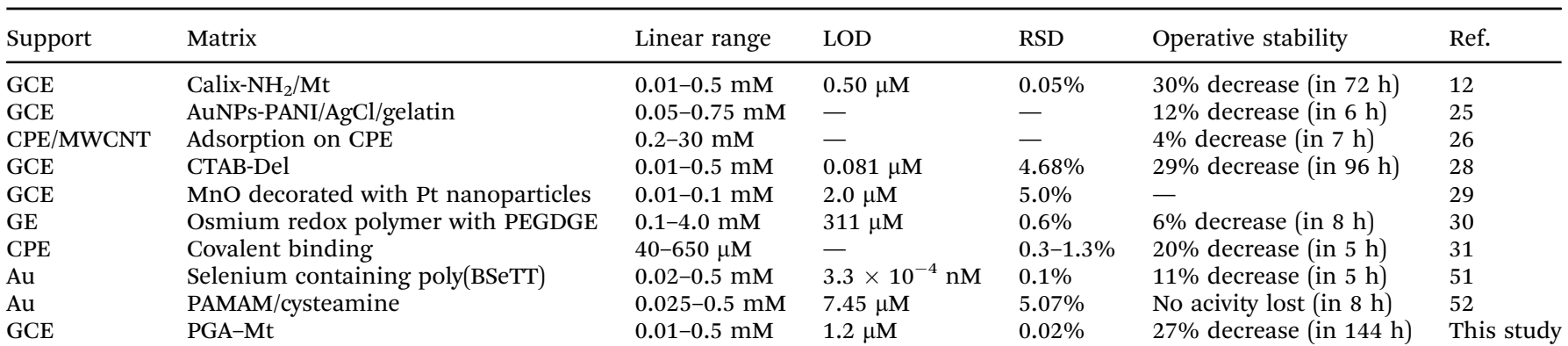

GCE: glassy carbon electrode; CNT: carbon nanotube; CTAB: cetyltrimethyl ammonium bromide; CPE: carbon paste electrode; MWCNT: multiwalled carbon nanotube; AuNPs: gold nanoparticles; PEGDGE: poly(ethyleneglycol) (400) diglycidylether; MnO: manganese oxide; PANI: polyaniline; AgCl: silver chloride; Calix: calixarene.

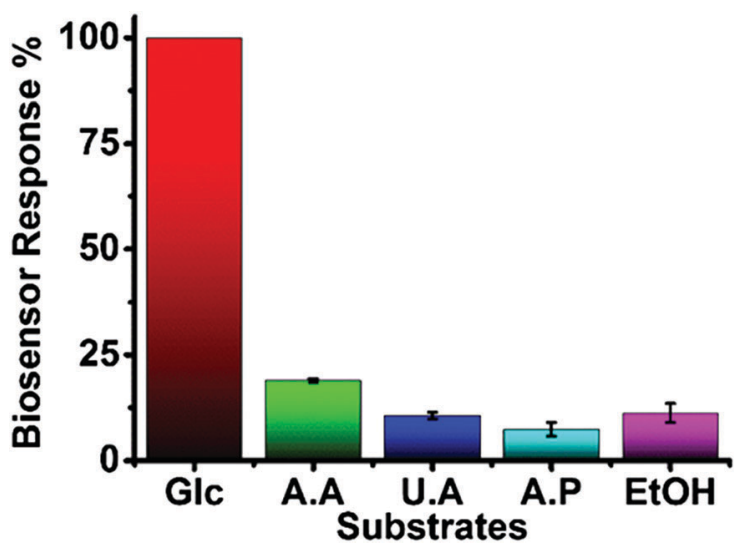

Fig. 10 Effect of interference by several compounds on the glucose sensor response of the PGA-Mt/POx biosensor utilized (in $50 \mathrm{mM} \mathrm{pH} 6.0 \mathrm{~PB}$, $-0.7 \mathrm{~V}$; error bars indicate S.D. of three trials; the biosensor responses of all compounds were defined as relative. AA: ascorbic acid; UA: uric acid; AP. 3-acetamidophenol; EtOH: ethanol).

Table 2 Glucose fillings for different beverages calculated by using both PGA-Mt/POx and a spectrophotometric method (Results are given as mean \pm standard deviation of three measurements)

\begin{tabular}{lccc}
\hline Sample & $\begin{array}{l}\text { PGA-Mt/POx } \\
(\mathrm{mM} \pm \text { S.D. })\end{array}$ & $\begin{array}{l}\text { Trinder reagent } \\
(\mathrm{mM} \pm \text { S.D. })\end{array}$ & $\begin{array}{l}\text { Recovery } \\
(\%)\end{array}$ \\
\hline Coke & $29.05 \pm 1.23$ & $28.435 \pm 1.24$ & 102 \\
Fizzy & $26.945 \pm 0.7$ & $28.05 \pm 0.69$ & 96
\end{tabular}

Trinder Reaction (a commercially available enzyme assay kit) was used to investigate the samples spectrophotometrically. In this reaction, glucose oxidase oxidizes glucose to D-gluconic acid with the creation of hydrogen peroxide. After the measurements were taken, the amount of glucose was calculated, and the results are given in Table 2 .

\section{Conclusions}

Clay minerals are increasingly drawing attention as an immobilization matrix for biological materials. Various types of enzymes and microorganisms were immobilized using clays on the electrode surface to design electrochemical biosensors.
Among them, Mt is an important type of clay due to its high adsorption capacity, specific surface area, and high cation exchange capacity, etc. Different types of monomers were used for the preparation of polymer/Mt nanocomposites via various methods. As far as we know, a PGA/Mt nanocomposite has not been synthesized before. Here, we reported the preparation of a novel PGA/Mt nanocomposite and its application as an immobilization material to fabricate biosensors. POx was utilized as a model enzyme. The proposed PGA-Mt/POx biosensor was optimized and characterized for glucose detection. Then, it was applied to detect glucose in real samples.

\section{Acknowledgements}

The authors also would like to thank TUBITAK (Program for the University Students at undergraduate level Program Number TUBITAK-2209 and Project number: 215Z194) and Ege University Research Funds (Project number: 2013FEN066). Dr D. O. Demirkol acknowledges The Turkish Academy of Sciences-Outstanding Young Scientists Award Program-2015 (TUBA-GEBIP). Authors thank to Assoc. of Prof. Dr Mustafa Can for his helps to take AFM images, Dr Murat Yavuz and Technician Süreyya Kaçar (Dicle University Science and Technology Research and Application Center (DUBTAM)) for TEM images.

\section{Notes and references}

1 N. An, C. H. Zhou, X. Y. Zhuang, D. S. Tong and W. H. Yu, Appl. Clay Sci., 2015, 114, 283-296.

2 G. Nagendrappa, Appl. Clay Sci., 2011, 53, 106-138.

3 E. I. Unuabonah and A. Taubert, Appl. Clay Sci., 2014, 99, 83-92.

4 S. Maiti, A. Pramanik, S. Chattopadhyay, G. De and S. Mahanty, J. Colloid Interface Sci., 2016, 464, 73-82.

5 M. Jafarbeglou, M. Abdouss, A. M. Shoushtari and M. Jafarbeglou, RSC Adv., 2016, 6, 50002-50016.

6 C. Mousty, Anal. Bioanal. Chem., 2010, 396, 315-325.

7 M. Kotal and A. K. Bhowmick, Prog. Polym. Sci., 2015, 51, 127-187.

8 M. Seleci, D. Ag, E. E. Yalcinkaya, D. O. Demirkol, C. Guler and S. Timur, RSC Adv., 2012, 2, 2112-2118. 
9 B. Demir, M. Seleci, D. Ag, S. Cevik, E. E. Yalcinkaya, D. O. Demirkol, U. Anik and S. Timur, RSC Adv., 2013, 3, 7513.

10 F. Demir, B. Demir, E. E. Yalcinkaya, S. Cevik, D. Odaci Demirkol, U. Anik and S. Timur, RSC Adv., 2014, 4, 50107-50113.

11 D. Songurtekin, E. E. Yalcinkaya, D. Ag, M. Seleci, D. O. Demirkol and S. Timur, Appl. Clay Sci., 2013, 86, 64-69.

12 B. Sonmez, S. Sayin, E. E. Yalcinkaya, D. A. Seleci, H. B. Yildiz, D. O. Demirkol and S. Timur, RSC Adv., 2014, 4, 62895-62902.

13 M. A. Tasdelen, W. Van Camp, E. Goethals, P. Dubois, F. Du Prez and Y. Yagci, Macromolecules, 2008, 41, 6035-6040.

14 S. I. Marras, I. Zuburtikudis and C. Panayiotou, J. Mater. Sci., 2010, 45, 6474-6480.

15 M. S. Rama and S. Swaminathan, Ind. Eng. Chem. Res., 2010, 49, 2217-2227.

16 E. E. Yalçinkaya, J. Mater. Sci., 2014, 49, 749-757.

17 E. E. Yalçinkaya, M. Balcan and Ç. Güler, Mater. Chem. Phys., 2013, 143, 380-386.

18 E. E. Yalcinkaya, J. Compos. Mater., 2015, 50, 533-542.

19 W. H. Hoidy, M. B. Ahmad, E. A. J. Al-Mulla and N. A. B. Ibrahim, J. Appl. Sci., 2010, 10, 97-106.

20 M. Liu, M. Pu and H. Ma, Compos. Sci. Technol., 2012, 72, 1508-1514.

21 F. B. Barlas, D. Ag Seleci, M. Ozkan, B. Demir, M. Seleci, M. Aydin, M. A. Tasdelen, H. M. Zareie, S. Timur, S. Ozcelik and Y. Yagci, J. Mater. Chem. B, 2014, 2, 6412.

22 S. M. Datta, Appl. Clay Sci., 2013, 80-81, 85-92.

23 H. Amine, O. Karima, B. M. El Amine, M. Belbachir and R. Meghabar, J. Polym. Res., 2005, 12, 361-365.

24 T. Wongnate and P. Chaiyen, FEBS J., 2013, 280, 3009-3027.

25 D. Odaci, A. Telefoncu and S. Timur, Bioelectrochemistry, 2010, 79, 108-113.

26 C. Ozdemir, F. Yeni, D. Odaci and S. Timur, Food Chem., 2010, 119, 380-385.

27 D. Odaci, A. Telefoncu and S. Timur, Sens. Actuators, B, 2008, 132, 159-165.

28 M. Maiga, E. E. Yalcinkaya, B. Sonmez, D. Puglia, M. Yavuz, D. O. Demirkol, J. M. Kenny and S. Timur, Sens. Actuators, B, 2016, 235, 46-55.

29 K. V. Ozdokur, B. Demir, E. Yavuz, F. Ulus, Ç. Erten, I. Aydin, D. O. Demirkol, L. Pelit, S. Timur and F. N. Ertaş, Sens. Actuators, B, 2014, 197, 123-128.

30 S. Timur, Y. Yigzaw and L. Gorton, Sens. Actuators, B, 2006, 113, 684-691.
31 H. Liden, J. Volc, G. Marko-Varga and L. Gorton, Electroanalysis, 1998, 10, 223-230.

32 C. K. Peterbauer and J. Volc, Appl. Microbiol. Biotechnol., 2010, 85, 837-848.

33 J. Wang and Q. Chen, Anal. Chim. Acta, 1995, 312, 39-44.

34 P. Trinder, J. Clin. Pathol., 1969, 22, 158-161.

35 Y. Ikada and H. Tsuji, Macromol. Rapid Commun., 2000, 21, 117-132.

36 K. A. Athanasiou, G. G. Niederauer and C. M. Agrawal, Biomaterials, 1996, 17, 93-102.

37 M. H. Hartmann, Biopolym. Renewable Resour., 1998, 367-411.

38 R. Simons, S. N. Guntari, T. K. Goh, G. G. Qiao and S. A. Bateman, J. Polym. Sci., Part A: Polym. Chem., 2012, 50, 89-97.

39 V. Katiyar and H. Nanavati, Polym. Eng. Sci., 2011, 51, 2066-2077.

40 A. A. Sapalidis, F. K. Katsaros and N. K. Kanellopoulos, Nanocompos. Polym. Anal. Methods, 2011, 29-50.

41 I. Çakar, K. V. Özdokur, B. Demir, E. Yavuz, D. O. Demirkol, S. Koçak, S. Timur and F. N. Ertaş, Sens. Actuators, B, 2013, 185, 331-336.

42 O. Barbosa, C. Ortiz, Á. Berenguer-Murcia, R. Torres, R. C. Rodrigues and R. Fernandez-Lafuente, RSC Adv., 2014, 4, 1583.

43 C. Mousty, Appl. Clay Sci., 2004, 27, 159-177.

44 D. O. Demirkol, H. B. Yildiz, S. Sayin and M. Yilmaz, RSC Adv., 2014, 4, 19900-19907.

45 A. Mignani, E. Scavetta and D. Tonelli, Anal. Chim. Acta, 2006, 577, 98-106.

46 D. Shan, W. Yao and H. Xue, Electroanalysis, 2006, 18, 1485-1491.

47 E. Guler, H. C. Soyleyici, D. O. Demirkol, M. Ak and S. Timur, Mater. Sci. Eng., C, 2014, 40, 148-156.

48 D. Shan, C. Mousty and S. Cosnier, Anal. Chem., 2004, 76, 178-183.

49 D. Shan, S. Cosnier and C. Mousty, Anal. Chem., 2003, 75, 3872-3879.

50 Q. Shi, Q. Li, D. Shan, Q. Fan and H. Xue, Mater. Sci. Eng., C, 2008, 28, 1372-1375.

51 T. C. Gokoglan, S. Soylemez, M. Kesik, S. Toksabay and L. Toppare, Food Chem., 2015, 172, 219-224.

52 M. Yuksel, M. Akin, C. Geyik, D. O. Demirkol, C. Ozdemir, A. Bluma, T. Höpfner, S. Beutel, S. Timur and T. Scheper, Biotechnol. Prog., 2011, 27, 530-538. 